\section{Regards sur l'économie allemande}

Bulletin économique du CIRAC

$89 \mid 2008$

Varia

\title{
Théorie des organisations
}

EBERLE Thomas S., HOIDN Sabine, DIKAVICA Katarina (eds), Fokus

Organisation. Sozialwissenschaftliche Perspektiven und Analysen /

PICOT Arnold, DIETL Helmut, FRANCK Egon, Organisation. Eine

ökonomische Perspektive

\section{(2)enEdition}

\section{Journals}

Édition électronique

URL : http://journals.openedition.org/rea/3153

DOI : $10.4000 /$ rea.3153

ISBN : 978-2-8218-0874-4

ISSN : 1965-0787

Éditeur

CIRAC

Édition imprimée

Date de publication : 1 décembre 2008

ISSN : 1156-8992

\section{Référence électronique}

«Théorie des organisations », Regards sur l'économie allemande [En ligne], 89 | décembre 2008, mis en

ligne le 13 janvier 2009, consulté le 22 septembre 2020. URL : http://journals.openedition.org/rea/

3153 ; DOI : https://doi.org/10.4000/rea.3153

Ce document a été généré automatiquement le 22 septembre 2020.

(c) CIRAC 


\section{Théorie des organisations}

EBERLE Thomas S., HOIDN Sabine, DIKAVICA Katarina (eds), Fokus

Organisation. Sozialwissenschaftliche Perspektiven und Analysen /

PICOT Arnold, DIETL Helmut, FRANCK Egon, Organisation. Eine

ökonomische Perspektive

\section{RÉFÉRENCE}

EBERLE Thomas S., HOIDN Sabine, DIKAVICA Katarina (eds), Fokus Organisation.

Sozialwissenschaftliche Perspektiven und Analysen, UVK Verlagsgesellschaft,

Constance, 2007, 380 p.

PICOT Arnold, DIETL Helmut, FRANCK Egon, Organisation. Eine ökonomische

Perspektive, $5^{\mathrm{e}}$ édition, Schäffer Poeschel Verlag, Stuttgart, 2008, $472 \mathrm{p}$.

1 Voici deux publications traitant d'un même concept, l'organisation, dont l'étendue varie toutefois selon l'angle d'approche défini par les auteurs. Rattaché aux sciences sociales, le terme recouvre alors un ensemble d'institutions au sens large (T. EBERLE et al.) : entreprises bien sûr, mais aussi universités, églises et tribunaux selon ce recueil publié en hommage à l'œuvre scientifique d'Emil Walter-Bush, professeur émérite et spécialiste de la psychologie sociale. D’un point de vue économique cependant (A. ARNOLD et al.), la notion d'organisation repose sur l'entreprise, son cadre juridique (politique de la concurrence et droit des sociétés) et l'interdépendance croissante des acteurs économiques (sous-traitance, coopération interentreprises et réseaux). En phase avec les évolutions récentes de l'économie, la $5^{\mathrm{e}}$ édition de ce manuel est augmentée d'un chapitre sur l'organisation de l'innovation qui examine les questions de propriété intellectuelle et d'appropriation du produit de l'innovation. (sh) 